Somnologie $2010 \cdot 14: 213-220$

DOI 10.1007/s11818-010-0478-5

Received: 27 November 2009

Accepted: 18 May 2010

Published online: 14 August 2010

(c) Springer-Verlag 2010

\author{
S. Brand ${ }^{1} \cdot$ K. Opwis ${ }^{2} \cdot$ M. Hatzinger $^{3} \cdot$ E Holsboer-Trachsler $^{1}$ \\ ${ }^{1}$ Depression Research Unit, Psychiatric Hospital of the University of Basel \\ 2 Department of Psychology, University of Basel \\ ${ }^{3}$ Psychiatric Outpatient Department of the University of Basel
}

\title{
REM sleep is related to the transfer of implicit procedural knowledge following metacognitive learning
}

A further line of research suggests that

Numerous studies have shown that sleep is crucial both for memory consolidation and memory enhancement $[16,25,26]$; see [8] for an overview. Accordingly, sleep loss seems to lead to impaired memory consolidation [16]. As a general observation, reactivation of memory traces during nonREM sleep-rich sleep seems particularly beneficial for the consolidation of declarative memory processes, whereas reactivation of memory traces during REM sleeprich sleep seems to be particularly beneficial for emotional and implicit procedural memory consolidation $[18,27]$. Moreover, Smith et al. $[22,23,24]$ could repeatedly demonstrate that solving an implicit procedural task, that is, the Tower of Hanoi, was associated with increased REM sleep. However, Piosczyk et al. [17] summarized that different sleep-related processes are involved in memory consolidation. Moreover, Stickgold and Walker [27] showed that for visual texture discrimination learning, the multiplication of early night SWS (slow-wave sleep) and late night REM sleep was predictive for improved performance. In particular, the amount of SWS during the first quarter of the night multiplied by the amount of REM-S during the last quarter of the night correlated strongly and statistically significantly with the learning improvement $(r=0.89)$. Therefore, it is believed that memory reactivation during SWS may lead to a tagging of synapses which are subsequently strengthened during REM sleep (cf. [18]), suggesting that both nonREM and REM sleep might be involved in memory processing. during REM sleep the brain is processing associative memories rather than consolidating memory traces (cf. [27]). According to this view, sleep inspires insight [30] and the acquisition of implicit knowledge [9]. If this is true, then one would expect that processes to enhance the transfer of implicit procedural knowledge should be observed after REM sleep. However, the impact of REM sleep on the transfer of implicit procedural knowledge is currently not known.

Commonly, transfer is defined as the successful application of acquired knowledge in response to a task different from the one during the knowledge acquisition situation [28]. Moreover, achieving transfer is easier when similarity of surface features of the learning and transfer tasks is high (proximal transfer) than when similarity is low (distal transfer) [29]. In a previous study we could show that proximal and distal transfer was enhanced after metacognitive stimulation [4]. The term metacognition refers to the knowledge with which implicit procedural knowledge is applied ("knowing how to do"; cf. $[7,15])$. Participants in our previous study improved the transfer of implicit procedural knowledge after the use of metacognition, that is, after the use of knowledge with which implicit procedural knowledge is applied. Most importantly, the use of metacognition implicitly enhanced the understanding of the deep structure of problems, i.e., it facilitated an accurate grasp of the problem structure and the underlying problem solving algorithm, though without explicit knowledge.
In the present study, we combined both the beneficial effect of metacognition for the transfer of implicit procedural knowledge and sleep to further facilitate cognitive processes. The aim of the present study was, therefore, to explore the impact of sleep on the transfer of implicit procedural knowledge after metacognitive stimulation, where metacognitive stimulation is understood as a set of questions to enhance metacognition (see Procedure for more details). Two hypotheses were formulated: first, in a previous study, we could show that both proximal and distal transfer of implicit procedural knowledge was increased after metacognitive stimulation [4]; thus, we expected to replicate these results. Second, following Stickgold and Walker [27], Fischer et al. [9], and Smith et al. [22, 23, 24] during REM sleep the brain is processing associative memories and memory processes related to procedural knowledge; therefore, we expected that the transfer of implicit procedural knowledge should be associated with increased REM sleep.

\section{Method}

\section{Sample}

A total of 21 right-handed young adults (mean age in years: $M=19.49 ; S D=0.87$ ) took part in the study. To reduce the influence of confounding variables, only female participants were recruited. They were recruited from a high school in Basel, Switzerland. First, participants were informed about the aims and the procedure of the study, and written informed 
Tab. 1 Descriptive overview of the sleep variables related to the baseline and the assessment night, separated by learning condition (with and without metacognitive stimulation). A statistical overview of the sleep variables shows the relationship between the baseline and the assessment night, separated by learning condition (with and without metacognitive stimulation)

\begin{tabular}{|c|c|c|c|c|c|c|c|c|c|c|}
\hline & \multicolumn{2}{|l|}{ Baseline night } & \multicolumn{2}{|c|}{ Assessment night } & \multicolumn{2}{|c|}{ Factor time } & \multicolumn{2}{|c|}{ Factor group } & \multicolumn{2}{|c|}{$\begin{array}{l}\text { Time by group inter- } \\
\text { action }\end{array}$} \\
\hline & $\begin{array}{l}\text { Without MC } \\
n=11\end{array}$ & $\begin{array}{l}\text { With MC } \\
n=10\end{array}$ & $\begin{array}{l}\text { Without MC } \\
n=11\end{array}$ & $\begin{array}{l}\text { With MC } \\
n=10\end{array}$ & $F$ & $\eta^{2}$ & $F$ & $\eta^{2}$ & $F$ & $\eta^{2}$ \\
\hline SPT (min) & $414.43(11.49)$ & $412.50(18.29)$ & $415.00(8.94)$ & $416.10(13.43)$ & 0.81 & 0.041 & 0.37 & 0.042 & 0.06 & 0.003 \\
\hline TST (min) & $408.75(11.09)$ & $407.15(11.21)$ & $410.81(9.98)$ & $409.80(9.92)$ & 0.56 & 0.011 & 0.26 & 0.021 & 0.01 & 0.001 \\
\hline SE (\%) & $95.70(0.46)$ & $94.61(2.58)$ & $96.11(0.94)$ & $95.60(1.42)$ & 0.12 & 0.001 & 0.14 & 0.015 & 0.03 & 0.002 \\
\hline $\mathrm{SOL}(\min )$ & 4.59 (3.19) & $4.40(2.78)$ & $4.54(2.82)$ & $3.86(2.44)$ & 1.56 & 0.045 & 0.98 & 0.031 & $8.83^{* *}$ & 0.256 \\
\hline WASO (number) & $3.50(1.63)$ & $4.10(0.32)$ & $2.63(0.45)$ & $2.90(0.52)$ & $18.83^{* * *}$ & 0.495 & 1.64 & 0.081 & 0.36 & 0.001 \\
\hline WASO (min) & $12.78(2.65)$ & $16.35(10.68)$ & $8.98(2.05)$ & $7.03(4.56)$ & $12.34^{* *}$ & 0.125 & 2.01 & 0.090 & $14.56^{* *}$ & 0.25 \\
\hline Stage 1 (min) & $7.41(1.60)$ & $11.20(3.32)$ & $5.13(1.02)$ & $5.35(1.76)$ & $61.83^{* * *}$ & 0.765 & $2.22^{*}$ & 0.275 & $11.99^{* *}$ & 0.387 \\
\hline Stage 2 (min) & $180.59(37.74)$ & $179.00(21.54)$ & $160.10(20.98)$ & $156.70(10.28)$ & $31.39^{* * *}$ & 0.623 & 0.059 & 0.003 & 0.056 & 0.003 \\
\hline Stage 3 (min) & $32.13(10.23)$ & $27.15(3.67)$ & $29.45(9.22)$ & $25.10(3.28)$ & $48.07^{* * *}$ & 0.717 & 2.08 & 0.098 & 0.857 & 0.043 \\
\hline Stage 4 (min) & $88.21(18.20)$ & $79.75(7.28)$ & $90.55(17.53)$ & $82.10(6.10)$ & $18.80^{* * *}$ & 0.497 & 1.99 & 0.095 & 0.000 & 0.000 \\
\hline REM-S (min) & $101.18(9.39)$ & $94.81(38.43)$ & $106.00(9.59)$ & $134.90(30.77)$ & $186.44^{* * *}$ & 0.908 & 1.09 & 0.054 & $115.01^{* * *}$ & 0.858 \\
\hline REM-SL (min) & $105.93(35.76)$ & $97.20(27.69)$ & $115.08(40.10)$ & 84.40 (19.28) & 0.70 & 0.036 & $3.98^{*}$ & 0.32 & $25.52^{* * *}$ & 0.573 \\
\hline
\end{tabular}

consent was obtained. The study was performed in accordance with the ethical standards laid down in the Declaration of Helsinki. Second, participants completed four questionnaires focusing on depressive symptoms [31], sleepiness during the day (ESS [12]), and sleep complaints (ISI [2]). For the depression and sleepiness questionnaires, scores had to be within the range of healthy normative adult populations as indicated by the textbooks of the questionnaires (that is to say: Depression scale: healthy people: $\mathrm{x}<8$ (range $=0-$ 48) points; for the sleepiness scale: $x<6$ out of 18 points). For the Insomnia Severity Index (ISI), no scores were expected with regard to difficulties to initiate sleep, to maintain sleep, to wake up early in the morning, or to suffer from a reduction of performance related to sleep. The participants then completed the Horne and Ostberg questionnaire related to the chronotype [1] to assure that all participants belonged to the same chronotype; in our case, all participants were so-called larks, that is to say: they preferred to go to bed rather early in the evening and to get up rather early in the morning (median: 10; range $=7-13$ on a scale ranging from $7-28$ points; range for larks $<14$ points).

Third, since the task of a high-school graduate consists mainly in acquiring (declarative) knowledge, participants were included who indicated to have suffi- cient, but not extraordinarily low or high marks. In doing so, sleep alterations due to "job-related" strain should be avoided. Fourth, participants had to indicate that they were never previously exposed to the tasks. In addition, the high-school teachers for mathematics and psychology assured that they have never introduced and solved the tasks during class. Fifth, a brief psychiatric interview was conducted to ensure that participants did not suffer from any psychiatric and sleep disorder, such as obstructive breathing, snoring or sleepwalking, RLS and PLMS. Sixth, only participants who reported not using any mood and memory-enhancing substances, such as methylephenidate or modafinil, were included. Moreover, 2 weeks prior to the start of the study, participants were asked to reduce a possible intake of any sleep- and mood-altering substances (alcohol, caffeine, nicotine, cannabis) and to stop the intake during the period of the sleep-EEG recordings. Of the 30 female candidates approached, 23 met the criteria $(76.67 \%$; 3 were familiar with the tasks or with similar tasks; 4 reported current sleep complaints). Two participants withdrew from the study; thus, the sample consisted of 21 female participants (70\%).

\section{Study design}

First, participants were randomly assigned to one of two experimental conditions: the implicit procedural tasks in the learning phase had to be solved either with $(n=10)$ or without metacognitive stimulation ( $n=11$; see explanations below). Second, two nights of polysomnographic sleep registration were followed in the sleep lab. To avoid changes in sleep patterns due to hormonal changes, all sleepEEG recordings were performed during the second half of the menstrual cycle of the female participants. Prior to the sleep registration, participants did not perform any strenuous physical activity. The first sleep-EEG registration night was a baseline night. The portable sleep-EEG device was applied at 8:30 p.m. Afterwards, participants could read or complete their homework. At 10:15 p.m. they went to bed and the lights were turned off $15 \mathrm{~min}$ later. In the morning, participants were woken at 6:00 a.m., if they did not wake up spontaneously. The baseline night was introduced, first, to assure that subjective sleep indication also matched polysomnographic sleep assessment, and second, to check whether objectively assessed sleep between the two experimental conditions differed systematically. This, however, was not the case ( $\bullet$ Tab. 1). The assessment night was scheduled as follows: first, the 
portable sleep-EEG device was applied at 8:30 p.m. At 8:45 p.m., participants completed the tasks of the learning phase (see details below). Depending on the experimental condition, they had to solve the Tower of Hanoi problem ( $\mathrm{ToH})$ with or without metacognitive stimulation. The entire learning phase lasted for no more than about $15 \mathrm{~min}$. Then, participants went to bed, and the lights were switched off at about 10:30 p.m. In the morning, identical to the study of Rauchs et al. [19], there was a 15-min interval between waking and solving the transfer executive tasks, as described in detail below.

\section{Materials}

Three different tasks were used in the course of the experiment: (1) the Tower of Hanoi problem (ToH; e.g., [21]), the goal of which is to move a pyramid of variously sized disks from one peg to another. Only one disk can be moved at a time and it can never be placed on a smaller disk (- Fig. 1). Strictly, although the Tower of Hanoi problem is not a "pure" procedural task (see [23]), the task has undoubtedly very large procedural components, to the extent that solving the task takes place unconsciously (cf. [24]). (2) In the Hobbits and Orcs problem (HOP), the goal is to get three Hobbits and three Orcs across a river in a boat. The boat, however, has room for only two people and there must never be more Orcs than Hobbits on either side of the river (• Fig. 2; for a more detailed description of the Hobbits and Orcs Problem, see [25]. Note that The Hobbits and Orcs Problem is also known as Missionaries and Cannibals Problem). (3) The goal of the Katona Card problem (KC; $[3,4,14]$ ) is to order a stack of six playing cards so that when they are dealt, they appear in ascending order. When dealing the cards, every second card is returned to the bottom of the stack. The challenge posed by this problem is to define the sequence of the cards in the stack (- Fig. 3).

\section{Procedure}

In the learning phase, participants were required to solve a $\mathrm{ToH}$ with three, four, and five disks. While the group of participants without metacognitive stimula-

Somnologie 2010 · 14:213-220 DOI 10.1007/s11818-010-0478-5

C) Springer-Verlag 2010

\section{S. Brand · K. Opwis · M. Hatzinger - E Holsboer-Trachsler \\ REM sleep is related to the transfer of implicit procedural knowledge following metacognitive learning}

\section{Abstract}

Objective. The hypothesis that REM sleep is also related to the transfer of implicit procedural knowledge was tested.

Methods. A total of 21 female adults (mean age: 19.49 years) took part in the study. After a baseline night, participants were randomly assigned to one of two conditions to solve a cognitive procedural task (Tower of Hanoi problem; $\mathrm{ToH}$ ); on the evening of the assessment night, one group solved the cognitive procedural task with and one group solved the task without metacognitive stimulation. The morning after the assessment night, participants solved three further transfer tasks (ToH with more disks; the Hobbits and Orcs problem; Katona's card problem).
Results. Participants with metacognitive stimulation showed an increased performance in all three transfer tasks. Moreover, these participants had a significantly increased REM sleep.

Conclusion. REM sleep seems to be related to metacognitively acquired implicit procedural knowledge. The transfer of the acquired implicit procedural knowledge does not seem to be limited to structurally similar tasks.

\section{Keywords}

Metacognition · Transfer - Implicit knowledge · Procedural knowledge · REM sleep . Sleep architecture

\section{REM-Schlaf mit Transfer impliziten prozeduralen Wissens nach metakognitivem Lernen assoziiert}

\section{Zusammenfassung}

Hintergrund und Fragestellung. REMSchlaf-reicher Schlaf wird mit der Verar beitung von implizitem und vor allem von prozeduralem Wissen assoziiert. Die Hypothese wurde geprüft, ob REM-Schlaf auch mit dem Transfer von implizitem prozeduralem Wissen assoziiert ist, um ähnliche und unähnliche Problemlöseaufgaben zu lösen. Studiendesign. An der Studie nahmen 21 junge Frauen (Alter: 19.49) teil. Nach einer Baseline-Nacht wurden die Teilnehmenden nach Zufallsprinzip 2 Bedingungen zugeordnet, um eine prozedurale Lernaufgabe (Turm von Hanoi; TvH) zu lösen; am Abend der Assessment-Nacht erlernte eine Gruppe die Aufgabe mit, die andere Gruppe erlernte die Aufgabe ohne metakognitive Stimulation. Am Morgen nach der Assessment-Nacht lösten alle Teilnehmenden 3 Transferaufgaben (TvH mit mehr Scheiben; Hobbits-und-
Orcs-Problem; Katonas Kartenproblem), die sich hinsichtlich der Oberflächenstruktur von der Lernaufgabe unterschieden.

Ergebnisse. Teilnehmende zeigten nach metakognitiver Stimulation verbesserte Transferleistungen; diese Leistungen waren mit einer Zunahme an REM-Schlaf assoziiert. Schlussfolgerung. REM-Schlaf scheint mit dem Transfer von metakognitiv erworbenem prozeduralem Wissen assoziiert zu sein. Die Transferleistungen zeigten sich vor allem auch bei jenen Transferaufgaben, die in ihrer Oberflächenstruktur der Lernaufgabe nicht ähnlich waren.

\section{Schlüsselwörter}

Metakognition · Transfer · Implizites Wissen . Prozedurales Wissen · REM-Schlaf · Schlafarchitektur 


\begin{tabular}{lccc}
\hline Moves & Left-hand peg & Intermediate peg & Right-hand peg \\
\hline A & & \\
B & & \\
Start & C & - & - \\
\hline
\end{tabular}

B

Move 1

C

A

Move 2

C

B

A

Move 3

C

B

A

Move 4

A

B

C

B

Move 6

A

A

B

Move 7 and stop

Fig. $1 \Delta$ Graph to solve the Tower of Hanoi problem (ToH) with three disks. A small disk, B middle disk, Clarge disk

tion had only the ToH rules explained to them, those in the group of participants with metacognitive stimulation were also asked to answer the following three questions out loud and in the order 1-2-3 [3, 4] before each move: (1) "How are you deciding which disk to move next?", (2) "How are you deciding where to move the next disk?", (3) "How do you know this is a good move?", i.e., the participants with metacognitive stimulation had to report on their own thinking. Note that these participants had to listen to and answer a question before each move. Hence, they needed more time for each move (cf. [3, 4]).
The next morning all participants were asked to solve the following three transfer tasks without metacognitive stimulation: one ToH executive task with six disks (structurally similar executive transfer task), the HOP and KC (structurally dissimilar executive transfer tasks). Participants were instructed to perform the transfer tasks as accurately as possible. What all these tasks have in common is that they can be solved by a recursive strategy in which the problems are successively broken down into subgoals and hence simplified. The ToH with six disks was a structurally similar executive transfer task, because it differed from the learning executive task only in the number and the position of the disks, but not in the recursive strategy to solve it. The HOP and $\mathrm{KC}$ are solved with the same recursive strategy, although they do not have any surface features in common with the ToH tasks in the learning phase; therefore, they can be described as structurally dissimilar transfer tasks.

The ToH tasks were solved as soon as the given tower was on the right-hand peg. Participants were allowed to correct their moves by moving the same disk several times. What participants were not allowed to do, however, was to go back to the beginning and start solving the problem all over again. In the HOP and $\mathrm{KC}$ tasks, on the other hand, participants had to succeed by demonstrating the right solution without being able to reverse any of the moves made. If the suggested solution did not lead to the goal, the participant was asked to start all over again. The number of moves required for the solution of the ToH executive tasks and the number of trials for the HOP and KC executive tasks were recorded as dependent variables. The reason for this last variable is that both the HOP and KC problems are what are known as well-structured problems that allow only one possible solution and require a specific sequence of submoves (cf. [25]). In addition, a stopwatch was used to record the time required to solve each problem (see also Brand et al. [4]; all dependent variables are shown in - Tab. 2). 


\section{Sleep recording}

An ambulatory EEG-system was applied (Oxford Medilog; electroencephalogram: $\mathrm{C}_{3}-\mathrm{A}_{2}, \mathrm{C}_{4}-\mathrm{A}_{1}$, electromyogram: two electrodes at the chin, electrooculogram: two electrodes at the right and left side). Recordings were scored off-line by two experienced and independent staff members of the sleep lab, following the scoring parameters of Rechtschaffen and Kales [20].

Parameters regarding sleep continuity (total sleep time, sleep period time, sleep onset latency, REM-sleep latency, sleep efficiency, number and time of awakenings after sleep onset) and sleep architecture (percentage and time spent in stages 1, 2, 3, 4; light sleep as aggregation of stages 1 and 2; slow wave or deep sleep as aggregation of stages 3 and 4; REM sleep) were collected shown in $\bullet$ Tab. 2.

\section{Statistical analyses}

A series of ANOVAs with the factors group (with vs. without metacognitive stimulation) and time (first vs. second night) was performed to calculate differences of objective sleep variables between the two groups with regard to the baseline and the assessment night. A series of t-tests was performed to calculate the differences of performance related to the tasks.

Correlations were performed with Pearson's $r$.

Test results with an alpha error of below 0.05 were reported as significant. However, we emphasized the effect sizes (d) (Cohen [5, 6]). Effect sizes for t-tests: $0.49 \geq d \geq 0.20$ indicate small (i.e., negligible practical importance), $0.79 \geq d \geq 0.50$ indicate medium (i.e., moderate practical importance), and $d \geq 0.80$ indicate large (i.e., crucial practical importance) effect sizes. Effect sizes for ANOVAs (partial eta squared $\left.\left[\eta^{2}\right]\right): 0.059 \geq \eta^{2} \geq 0.01$ indicate small (i.e., negligible practical importance), $0.139 \geq \eta^{2} \geq 0.06$ indicate medium (i.e., moderate practical importance), and $\eta^{2} \geq 0.14$ indicate large (i.e., crucial practical importance) effect sizes.

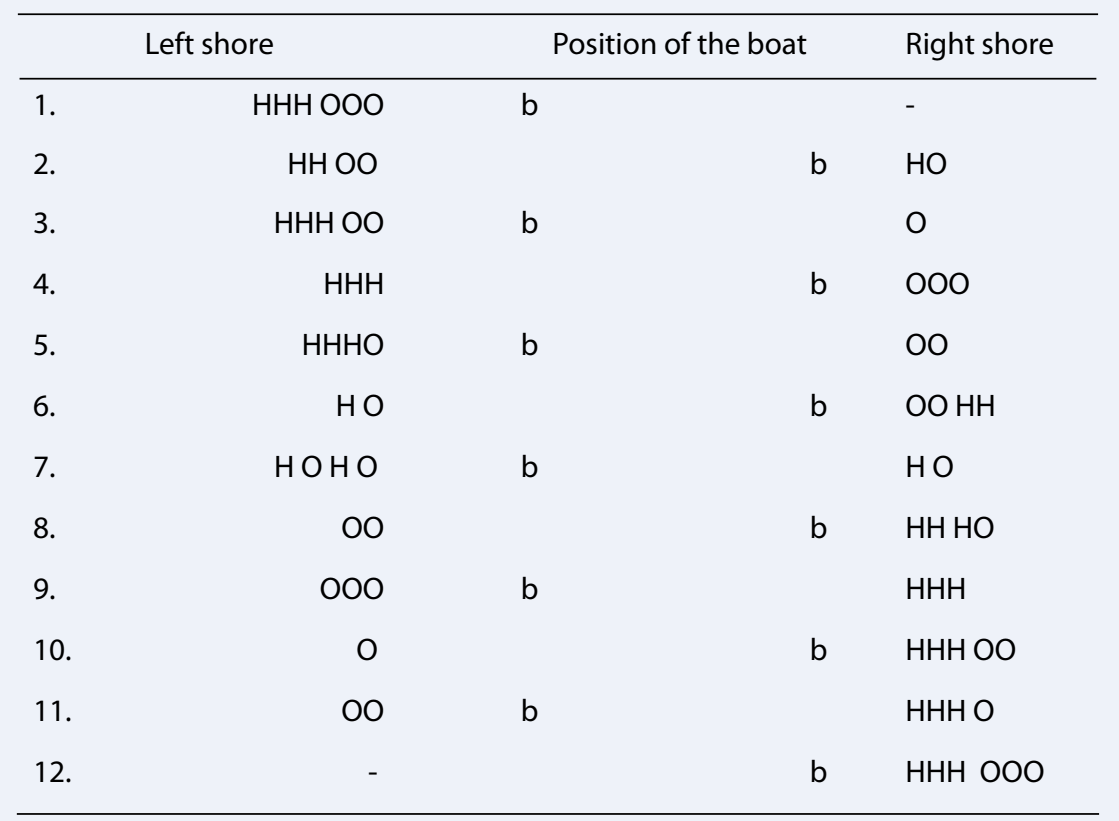

Fig. $2 \Delta$ Graph to solve the Hobbits and Orcs problem (HOP). $H$ Hobbit, $O$ Orc, $b$ boat

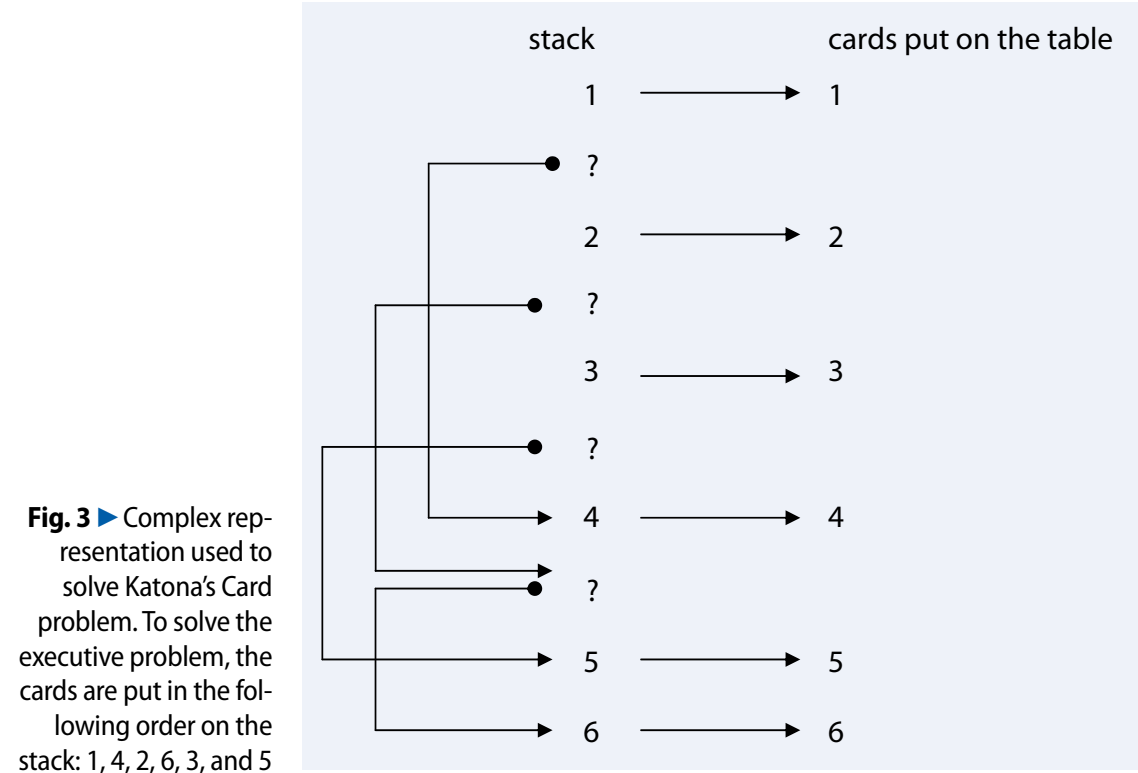

\section{Results}

\section{Sleep parameters between the baseline and the assessment night, between and within the two groups}

The descriptive and statistical overview of the sleep variables of the baseline and assessment night, separated by the learning condition are shown in $\bullet$ Tab. 1 .

For the baseline night, no differences in sleep parameters between the two groups were observed.

From baseline to assessment night (factor Time), WASO (number, min), S1,
$S_{2}$, and $S_{3}$ decreased, while $S_{4}$ and REM$\mathrm{S}$ increased.

Compared to the group without metacognitive stimulation, the group with metacognitive stimulation (factor Group) showed more $S_{1}$ and a shortened REM-S latency.

The time by group interaction revealed that in the group with metacognitive stimulation, from the baseline to the assessment night, and compared to the group without metacognitive stimulation, SOL, WASO ( $\mathrm{min}$ ), and $\mathrm{S} 1$ decreased, REM$S$ increased and the REM-S latency was shortened. 
Tab. 2 Performance during the learning and the transfer phase, separated by the condition of the learning phase (with or without metacognitive stimulation)

\begin{tabular}{|c|c|c|c|c|}
\hline & \multicolumn{2}{|l|}{ Conditions } & \multicolumn{2}{|l|}{ Statistics } \\
\hline & $\begin{array}{l}\text { Without metacog- } \\
\text { nitive stimulation }\end{array}$ & $\begin{array}{l}\text { With metacogni- } \\
\text { tive stimulation }\end{array}$ & t-tests & $d$ \\
\hline$n$ & 11 & 10 & & \\
\hline \multicolumn{5}{|c|}{$\begin{array}{l}\text { Learning phase in the } \\
\text { evening }\end{array}$} \\
\hline \multicolumn{5}{|l|}{$\mathrm{ToH} 3$} \\
\hline Moves $/ 7^{1}$ & $1.74(1.30)$ & $1.00(0.00)$ & $t(19)=1.28, p=0.237$ & 0.81 \\
\hline Time (s)/moves & $4.30(2.50)$ & $23.30(7.00)$ & $t(19)=-5.68, p<0.000$ & 3.61 \\
\hline \multicolumn{5}{|l|}{$\mathrm{ToH} 4$} \\
\hline Moves/15 1 & $2.23(1.14)$ & $1.31(0.29)$ & $t(19)=1.75, p=0.118$ & 1.11 \\
\hline Time (s)/moves & $2.50(1.00)$ & $16.50(5.30)$ & $\mathrm{t}(16)=-5.84, p<0.000$ & 3.67 \\
\hline \multicolumn{5}{|l|}{$\mathrm{ToH} 5$} \\
\hline Moves $/ 31^{1}$ & $1.34(0.07)$ & $1.22(0.06)$ & $\mathrm{t}(19)=0.92, p=0.383$ & 1.84 \\
\hline Time (s)/moves & $2.00(0.70)$ & $21.60(12.10)$ & $t(19)=-3.60, p=0.007$ & 2.29 \\
\hline \multicolumn{5}{|c|}{$\begin{array}{l}\text { Transfer phase in the } \\
\text { morning }\end{array}$} \\
\hline \multicolumn{5}{|c|}{ Proximal transfer task } \\
\hline \multicolumn{5}{|l|}{$\mathrm{ToH} 6$} \\
\hline Moves $/ 63^{1}$ & $2.22(0.23)$ & $1.23(0.06)$ & $\mathrm{t}(19)=9.21, p<0.001$ & 5.89 \\
\hline Time (s)/moves & $8.20(5.40)$ & $2.70(0.70)$ & $\mathrm{t}(19)=2.25, p=0.055$ & 1.43 \\
\hline \multicolumn{5}{|l|}{ Distal transfer task } \\
\hline \multicolumn{5}{|l|}{ Hobbits and Orcs } \\
\hline Trials & $3.40(0.89)$ & $1.00(0.00)$ & $\mathrm{t}(19)=6.00, p<0.001$ & 3.82 \\
\hline Time (min)/trials & $11.63(1.71)$ & $8.17(5.41)$ & $\mathrm{t}(19)=1.38, p<0.001$ & 0.86 \\
\hline \multicolumn{5}{|c|}{ Katona's card problem } \\
\hline Trials & $2.60(0.55)$ & $1.20(0.45)$ & $\mathrm{t}(19)=4.43, p=0.003$ & 2.79 \\
\hline Time (min)/trials & $9.32(5.27)$ & $8.34(6.34)$ & $\mathrm{t}(19)=0.26, p=0.799$ & 0.17 \\
\hline $\begin{array}{l}\text { ToH Tower of Hano } \\
\text { following formula: } y \\
\text { parison of the result }\end{array}$ & $\begin{array}{l}\text { Tower of Hanoi with th } \\
\text { The ratio of the exces } \\
\text { ent ToH tasks. }\end{array}$ & $\begin{array}{l}\text { disks. } 1 \text { The minimu } \\
\text { hoves to the minimur }\end{array}$ & $\begin{array}{l}\text { of moves is calculated with } \\
\text { number of moves allows a }\end{array}$ & the \\
\hline
\end{tabular}

\section{Performance of the learning and transfer phases}

The performance of the learning phase in the evening and the transfer phase in the morning (separate for the two groups) are summarized in $\bullet$ Tab. 2.

Descriptively, the group with metacognitive stimulation needed fewer moves to solve the $\mathrm{ToH}$ with three, four, and five disks in the learning phase. As mentioned above (cf. $[3,4]$ ), these participants needed more time to solve the tasks because they had to listen to and answer a question before each move.

In the transfer phase, the group with metacognitive stimulation needed fewer moves and trials to execute the proximal (ToH with six disks) and distal transfer tasks (HOP, KC). Moreover, the group with metacognitive stimulation generally needed less time to execute the tasks. and the performance of the transfer phase (all $r s<0.15, p>0.1$ ).

\section{Discussion}

The key findings of the present study are that metacognitive stimulation enhanced the transfer of implicit procedural knowledge and that this enhancement was related to significantly increased REM sleep.

Two hypotheses were formulated and each of these is now considered in turn.

First, we hypothesized that participants with metacognitive stimulation would show an improved transfer of implicit procedural knowledge, and the results confirmed this assumption. Thus, acquiring the "knowing how" seemed to be beneficial for solving further tasks with the identical inherent recursive executive strategy, however, with different surface features. Moreover, the pattern of results fits well with previous findings $[3,4]$.

Second, we hypothesized that an increased transfer of implicit procedural knowledge is related to REM sleep, and this second assumption could also be confirmed: compared to the control group, the group with metacognitive stimulation displayed highly increased REM sleep. This finding adds to the results from studies showing that REM-rich sleep promotes the solving of complex cognitive tasks [ 9 , $18,22,23,24,26,27]$. Our findings also correspond with the evidence that during REM sleep the brain is processing associative memories [26]. Importantly, the pattern of results suggests that REM sleep was related to metacognitively acquired solving of complex cognitive tasks to facilitate postsleep solving of other similar and dissimilar complex cognitive tasks. Moreover, REM-sleep latency was shortened in the group with metacognitive stimulation compared to the control group; this result suggests that REM-sleep onset occurred earlier during the nonREM-rich stage of sleep. In this view, it seemed that the SWS/ REM ratio did shift in favor of the REM sleep in those participants with previous metacognitive stimulation.

Tucker and Fishbein [28] have shown that the enhancement of declarative memory performance after sleep is associated with the initial task acquisition, that is to say: the better one consciously learns be- 
fore sleeping, the better she or he is able to apply this knowledge after sleeping. We may add that this pattern refers also to implicit solving of complex cognitive tasks, if we assume that REM sleep was related to the solving of complex cognitive tasks of participants whose initial task acquisition was increased via procedural metacognitive stimulation.

Several issues have to be raised against overgeneralizing the findings. First, exclusively female participants took part in the study; thus, the results may not be transferable to male participants. Second, there is evidence that practising novel tasks seems to lead to increased REM sleep [10]; thus, the increase of REM sleep in the group with metacognitive stimulation might rather reflect the response to novelty than the processing of previously acquired executive functioning. However, if this was true, one would have also expected a similar sleep pattern in the control group. Third, the results may be due to molecular and neuroendocrine vari- ables not assessed. Although the female participants were thoroughly assessed and possible confounding variables, e.g., cognitive abilities, previous exposure to similar tasks, menstrual cycle, strain, chronotype, and affect, were rigorously controlled, other confounding variables, such as creativity, motivation and physiological processes, cannot be excluded. However, these issues may be addressed for every study in the field, and thus rather reflect a methodological issue of general concern. Fourth, REM sleep was not experimentally manipulated. Therefore, we understand the present study as a preliminary experiment, which may promote other investigations. In addition, since we were mainly interested in the dichotomy between the acquisition of the learning task with or without metacognitive stimulation, neither a control group nor a wake control condition was introduced, which may be regarded as a further limitation. Fifth, although the tasks (ToH, HOP, KC) are quite well-known in cognitive psycholo- gy related to problem solving and executive functioning, to our knowledge, the $\mathrm{HOP}$ and $\mathrm{KC}$ have been applied for the first time as a paradigm to assess sleep-related cognitive processing. Thus, the present results and the present study design need replication. With regard to the $\mathrm{ToH}$, Smith et al. [22, 23, 24] repeatedly demonstrated that solving an implicit procedural task, such as the $\mathrm{ToH}$, was associated with increased REM sleep. Moreover, we could not assess the cognitive processes: Whereas it seems conceivable that participants acquired the implicit strategy to grasp the inherent algorithm to solve the proximal and distal transfer tasks, one may object as an alternative explanation that participants learned implicitly to approach the transfer tasks while applying metacognitive thinking. Therefore, it might be argued that the better results in the group with metacognitive stimulation were due to a prolonged learning phase (• Tab. 2). However, this prolonged learning phase was due to the fact that the participants

\section{Hier steht eine Anzeige.}

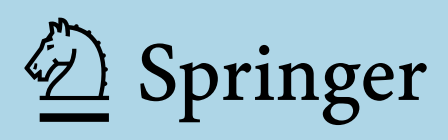


with metacognitive stimulation had to listen to questions and answer them before moving a disk. Hence, it is not surprising that these participants needed more time. Moreover, the change in sleep variables between the baseline and the assessment night might be due to the so-called first night effect. However, if this were the case, one would also expect similar sleep patterns in the control group. Finally, our data do not fit well with the results showing that SWS and REM sleep deprivation does not affect sleep-dependent memory consolidation [11], emphasizing that declarative and procedural memory consolidation during sleep might be more complex.

\section{Conclusion}

The pattern of results suggests that REM sleep seems to be related to the metacognitively acquired solving of complex cognitive tasks. Importantly, the transfer of the acquired way to solve the complex cognitive tasks did not seem limited to structurally similar tasks, since transfer effects were also observed for structurally dissimilar tasks. Given that psychotherapeutic treatment, among other goals, focuses on enhancing "thinking about the thinking" [13], implications of metacognitive strategies related to sleep should be further investigated in patients suffering from psychiatric disorders.

\section{Corresponding address}

\section{S. Brand}

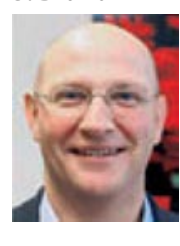

Depression Research Unit, Psychiatric Hospital of the University of Basel Wilhelm Klein-Str. 27, 4025 Basel Schweiz serge.brand@upkbs.ch

Acknowledgments. We thank Myriam Ryther for data collection and data entry. We are particularly thankful to Ms. Marielle Koenig and Mr. Vladimir Djurdjevic for sleep-EEG scoring. We also thank Anne-Louise Bornstein for proofreading the manuscript.

Conflict of interest. The study was conducted without external funding. The corresponding author states that there are no conflicts of interest.

\section{References}

1. Adan A, Almirall H (1991) Horne and Ostberg morningness-eveningness questionnaire: a reduced scale. Person Individ Diff 12:241-253

2. Bastien CH, Vallières A, Morin CM (2001) Validation of the insomnia severity index (ISI) as an outcome measure for insomnia research. Sleep Med 2:297307

3. Berardi-Coletta B, Buyer LS, Dominowski RL, Rellinger ER (1995) Metacognition and problem solving: A process-oriented approach. J Exp Psychol Learn Mem Cogn 2:205-223

4. Brand S, Reimer T, Opwis K (2003) Effects of metacognitive thinking and knowledge transfer in dyads on individual problem solving and transfer performance. Swiss J Psychol 62:251-561

5. Cohen J (1988) Statistical power analysis for the behavioral sciences. Lawrence Erlbaum Associates, Hillsdale, NJ

6. Cohen J (1994) The earth is round $(p<.05)$. Am Psychol 49:997-1003

7. Davidson JE, Deuser R, Sternberg RJ (1994) The role of metacognition in problem solving. In: Metcalfe J, Shimamura AP (eds). Metacognition: knowing about knowing. MIT Press, Cambridge MA, pp 207-226

8. Diekelmann S, Born J (2010) The memory function of sleep. Nat Rev Neurosci 11:114-126

9. Fischer S, Drosopoulos S, Tsen J, Born J (2006) Implicit learning - explicit knowing: a role for sleep in memory system interaction. J Cogn Neurosci 18:311-319

10. Fischer S, Hallschmid M, Elsner AL, Born J (2002) Sleep forms memory for finger skills. Proc Natl Acad Sci USA 99:11987-11991

11. Genzel L, Dresler M, Wehrle R et al (2009) Slow wave sleep and REM sleep awakenings do not affect sleep dependent memory consolidation. Sleep 32:302-310

12. Johns MW (1991) A new method for measuring daytime sleepiness: the Epworth sleepiness scale (ESS). Sleep 14:540-545

13. Kanfer FH, Reinecker H, Schmelzer D (2006) Selbstmanagement-Therapie. Ein Lehrbuch für die klinische Praxis [Self-management-therapy; a textbook for the clinical practice] 4th edn. Springer, Heidelberg

14. Katona G (1940) Organizing and memorizing. Columbia University Press, New York

15. Metcalfe J, Shimamura AP (1994) Metacognition: Knowing about knowing. MIT Press, Cambridge $\mathrm{MA}$

16. Nissen C, Kloepfer C, Nofzinger EA et al (2006) Impaired sleep-related memory consolidation in primary insomnia - a pilot study. Sleep 29:10681073

17. Piosczyk H, Kloepfer C, Riemann D, Nissen C (2009) Schlaf, Plastizität und Gedächtnis [Sleep, plasticity, and memory]. Somnologie 13:43-51

18. Rasch B, Born J (2007) Maintaining memories by reactivation. Curr Opin Neurobiol 17:698-703

19. Rauchs G, Bertran F, Guilery-Girard B et al (2004) Consolidation of strictly episodic memories mainly requires rapid eye movement sleep. Sleep 27:395401

20. Rechtschaffen A, Kales A (1968) A manual of standardized terminology, techniques and scoring system for sleep stages in human subjects. Brain Information Service, University of California, Los Angeles

21. Simon HA (1975) The functional equivalence of problem solving skills. Cogn Psychol 7:268-288
22. Smith CT (1995) Sleep states and memory processes. Behav Brain Res 69:137-145

23. Smith CT, Nixon MR, Nader RS (2004) Posttraining increases in REM sleep intensity implicate REM sleep in memory processing and provide a biological marker of learning potential. Learn Mem 11:714-719

24. Smith CT, Smith D (2003) Ingestion of ethanol just prior to sleep onset impairs memory for procedural but not declarative tasks. Sleep 26:185-191

25. Sternberg RJ (2006) Cognitive psychology, 4th edn. Thomson Wadsworth, Belmont CA

26. Stickgold R, Hobson JA, Fosse R, Fosse M (2001) Sleep, learning, and dreams: Off-line memory reprocessing. Science 294:1052-1057

27. Stickgold R, Walker M (2007) Sleep-dependent memory consolidation and reconsolidation. Sleep Med 8:331-343

28. Tucker MA, Fishbein W (2008) Enhancement of declarative memory performance following a daytime nap is contingent on strength of initial task acquisition. Sleep 31:197-203

29. Van Lehn K (1996) Cognitive skill acquisition. Annu Rev Psychol 47:513-539

30. Wagner U, Gais S, Haider H et al (2004) Sleep inspires insight. Nature 427:352-354

31. Zerssen D von (1976) Depressivitäts-Skala [Depression scale]. Hogrefe, Göttingen 